\title{
Research and Application of Management Accounting in PPP Project Performance Evaluation Based on AHP- EWM Model
}

\author{
Wenxi Wang ${ }^{1, \mathrm{a}, *}$ \\ ${ }^{1}$ Northeastern University, School of business administration,110819, Shenyang, China \\ a1134343964@qq.com
}

\begin{abstract}
This paper sets the performance evaluation index of the PPP（Public-Private Partnership） project and uses the entropy weight method to modify the index weight under the subjective analytic hierarchy process to make it more objective and accurate, to establish the performance evaluation system of the PPP project. The system helps to attract the government's attention to the critical indicators of the project, helps the government to comprehensively evaluate the project performance of cooperation with social capital, and provides the primary basis for the management and improvement of the PPP projects, to promote the further development of PPP projects.
\end{abstract}

Keywords: EWM model, PPP project, project performance evaluation, MATLAB.

\section{INTRODUCTION}

In recent years, the project operation mode of cooperation between government and social capital (PPP mode) has become more and more popular, and Chinese and even global scholars have conducted relevant research from various angles. Wang $\mathrm{Hao}^{[1]}$ discussed the definition and classification of PPP at the initial stage for reference of relevant policies and regulations. $\mathrm{Hu} \mathrm{Li}^{[2]}$ and others focused on the conflict of interests between the public and the private. This paper establishes a PPP project benefit allocation model based on shapely modification, which helps to coordinate the benefit allocation of all parties. Erik Hans $\mathrm{Klijn}^{[3]}$ shows the importance of researchers, the government, and the private sector to correctly treat PPP performance beyond the contract terms by investigating the impact of four important characteristics of PPP contracts on performance. Wang Yumei ${ }^{[4]}$ and others set up the Balanced Scorecard evaluation system from the PPP project's strategic objectives, further promoting the comprehensive evaluation of the overall performance of the project.

Starting from the Balanced Scorecard performance evaluation system, this paper studies to determine PPP project performance indicators' weight by integrating the subjective and objective evaluation models. Through several experts scoring, using AHP to get the subjective weight, and using the entropy weight method to modify it, finally, get the comprehensive and objective PPP project performance the index weight value.

\section{INTRODUCE THE EVALUATION INDEX}

Based on the balanced scorecard method, the evaluation index can be used to evaluate the performance of PPP projects from four dimensions: financial dimension, customer dimension, internal process dimension, learning, and growth ${ }^{[5]}$. Refer to relevant regulation, the following primary and secondary indicators can be obtained.

Index 1: Financial benefit of the project (A1)

PPP projects absorb both government and social capital, so the financial benefit of the project is an important aspect of the performance evaluation of both sides. Among them, we need to pay attention to whether the project is value for money (B1), whether the project investment can get appropriate income. The financial capacity of all parties (B2) affects the support of all aspects of the project. The construction of investment and financing mechanism (B3) is used to formulate the institutional mechanism of investment and financing, which affects the project investment and income.

Index 2: Balanced stakeholder satisfaction (A2)

As an urban construction project to solve urban 
problems, the stakeholders in PPP projects are more affected and closely linked. Government department satisfaction (B4) is based on whether the project input has corresponding output to meet the management needs, public social satisfaction (B5) is based on the project solving problems, other participants' satisfaction (B6) is affected by their respective benefits from the project, and the cooperation status (B7) determines the efficiency and results of the project.

Index 3: The control of the project process (A3)

To ensure the smooth progress of PPP projects and achieve the desired results, all aspects of the project process need to be monitored and adjusted in time. Fund forecast and control (B8), schedule forecast and management (B9), quality control management (B10), safety measures and management (B11), risk forecast and control (B12), and government supervision and quality inspection (B13) are closely related to project performance.

Index 4: Sustainable development (A4)

As an urban construction project, sustainable development is also a vital concern of the government and the public. The PPP project's fundamental purpose is to ensure the life benefits of citizens (B14) for a long time. The level of R \& D investment (B15) affects the iteration speed of the project, and the willingness of multi-party participation (B16) affects the construction effect of the project, all of which play an important role in the sustainable development ability of the project. Besides, only when the ecological and environmental benefits (B17) are taken seriously can the overall urban development foundation be sustainable for a long time.

\section{INTRODUCTION OF ENTROPY WEIGHT METHOD}

The entropy weight method (EWM) is an objective weighting method ${ }^{[6]}$. It evaluates the amount of information by analyzing the degree of information disorder reflected by information entropy to judge its effect on decision-making. The greater the entropy, the greater the amount of information contained, and the greater the effect on decision-making.

In this paper, the entropy weight method is used to modify the subjective weight under the analytic hierarchy process ${ }^{[7]}$, to get a more objective index weight, and then establish the PPP project performance evaluation index system. As the analytic hierarchy process is widely used, it will not be elaborated here.

Step 1: Compare each other and establish the initial judgment matrix. If $\mathrm{x}$ is more important than $\mathrm{y}$, and it is represented by 2 . Furthermore, if $x$ is not important, it is represented by 2 . In addition, if $y$ is important, it is indicated by 0 . If both are equally important, it is indicated by 1 .
Step 2: Calculate the relative importance weight.

$$
r_{j}=\sum_{i=1}^{n} a_{i j}
$$

Step 3: Establish the judgment matrix $A=\left(a_{i j}\right)_{n \times n}$.

$$
\left\{\begin{array}{c}
a_{i j}=r_{j}-r_{i}+1, \quad r_{j} \geq r_{i} \\
a_{i j}=\left(r_{i}-r_{j}+1\right)^{-1}, \quad r_{j} \leq r_{i}
\end{array}\right.
$$

Step 4: Use the analytic hierarchy process to calculate the subjective weight of A.

$$
=\frac{w_{j}}{\sum_{j=1}^{n} \sqrt[n]{\prod_{i=1}^{n} a_{i j}}}
$$

Step 5: Normalize judgment matrix A to get the standard matrix.

$$
\begin{aligned}
& \mathrm{Z}=\left(\mathrm{z}_{\mathrm{ij}}\right)_{\mathrm{n} \times \mathrm{n}} \\
\text { Among } & \mathrm{z}_{\mathrm{ij}}=\frac{\mathrm{a}_{\mathrm{ij}}}{\sum_{\mathrm{i}=1}^{\mathrm{n}} \mathrm{a}_{\mathrm{ij}}}
\end{aligned}
$$

Step 6: Calculate the information entropy of index $j$ in turn.

$$
\begin{gathered}
H_{j}=-\frac{1}{\ln n} \sum_{i=1}^{n} z_{i j} \ln z_{i j} \quad(i, j \\
=1,2, \ldots, n)
\end{gathered}
$$

Step 7: Calculate the information entropy weight of index $\mathrm{j}$ in turn.

$$
u_{j}=\frac{1-H_{j}}{n-\sum_{j=1}^{n} H_{j}}
$$

Step 8: Use information entropy weight to modify subjective weight to get index weight.

$$
y_{j}=\frac{H_{j} w_{j}}{\sum_{j=1}^{n} H_{j} w_{j}}
$$

\section{RESEARCH AND APPLICATION OF MANAGEMENT ACCOUNTING IN PROJECT PERFORMANCE EVALUATION BASED ON EWM MODEL}

\subsection{Data collection and analysis}

\subsubsection{Data collection}

In this paper, taking the sponge city project under PPP mode as an example, a total of 30 questionnaires were sent to professors and scholars in related fields, and finally, 20 were invited to evaluate the indicators. The questionnaire adopts a five-level scoring system, and the importance of evaluation is assigned from low to high in 
turn and quantified as scores: 20, 40, 60, 80100. Add all the score, as shown in Table 1.

the index scores to get the average value and calculate

Table 1 importance score of sponge city project performance evaluation index under PPP mode

\begin{tabular}{|c|c|c|c|}
\hline $\begin{array}{c}\text { First-rank evaluation } \\
\text { index }\end{array}$ & Average score & $\begin{array}{c}\text { Second-rank evaluation } \\
\text { index }\end{array}$ & Average score \\
\hline \multirow[t]{3}{*}{ 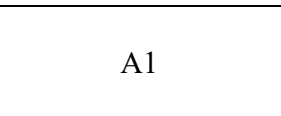 } & \multirow{3}{*}{88} & B1 & 88 \\
\hline & & $\mathrm{B} 2$ & 72 \\
\hline & & B3 & 80 \\
\hline \multirow{4}{*}{ A2 } & \multirow{4}{*}{76} & B4 & 88 \\
\hline & & B5 & 88 \\
\hline & & B6 & 76 \\
\hline & & B7 & 80 \\
\hline \multirow{6}{*}{ A3 } & \multirow{6}{*}{88} & $\mathrm{~B} 8$ & 92 \\
\hline & & B9 & 80 \\
\hline & & B10 & 92 \\
\hline & & B11 & 96 \\
\hline & & B12 & 96 \\
\hline & & B13 & 88 \\
\hline \multirow{4}{*}{ A4 } & \multirow{4}{*}{88} & B14 & 88 \\
\hline & & B15 & 76 \\
\hline & & B16 & 76 \\
\hline & & B17 & 88 \\
\hline
\end{tabular}

\subsubsection{Data analysis}

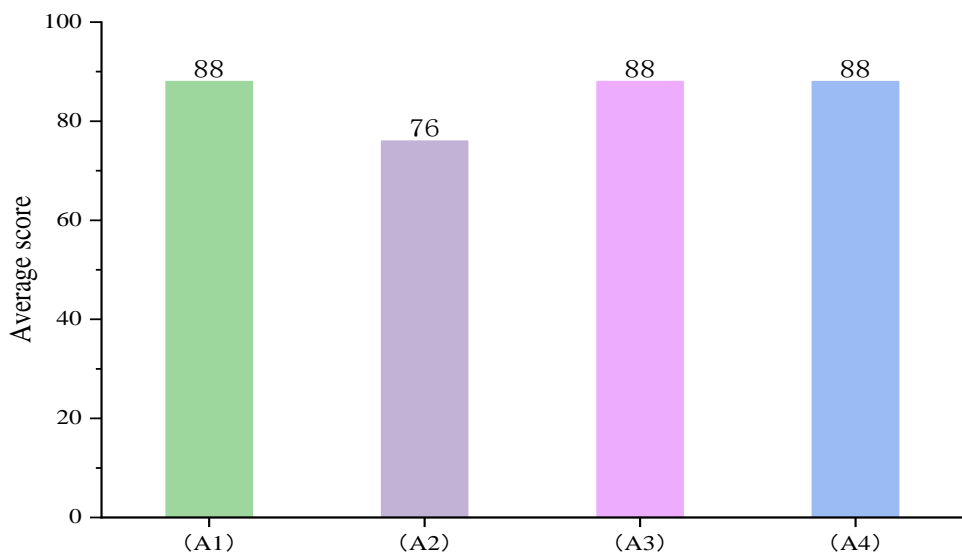

Fig.1 The importance score of the first level evaluation index of sponge city project performance under PPP mode

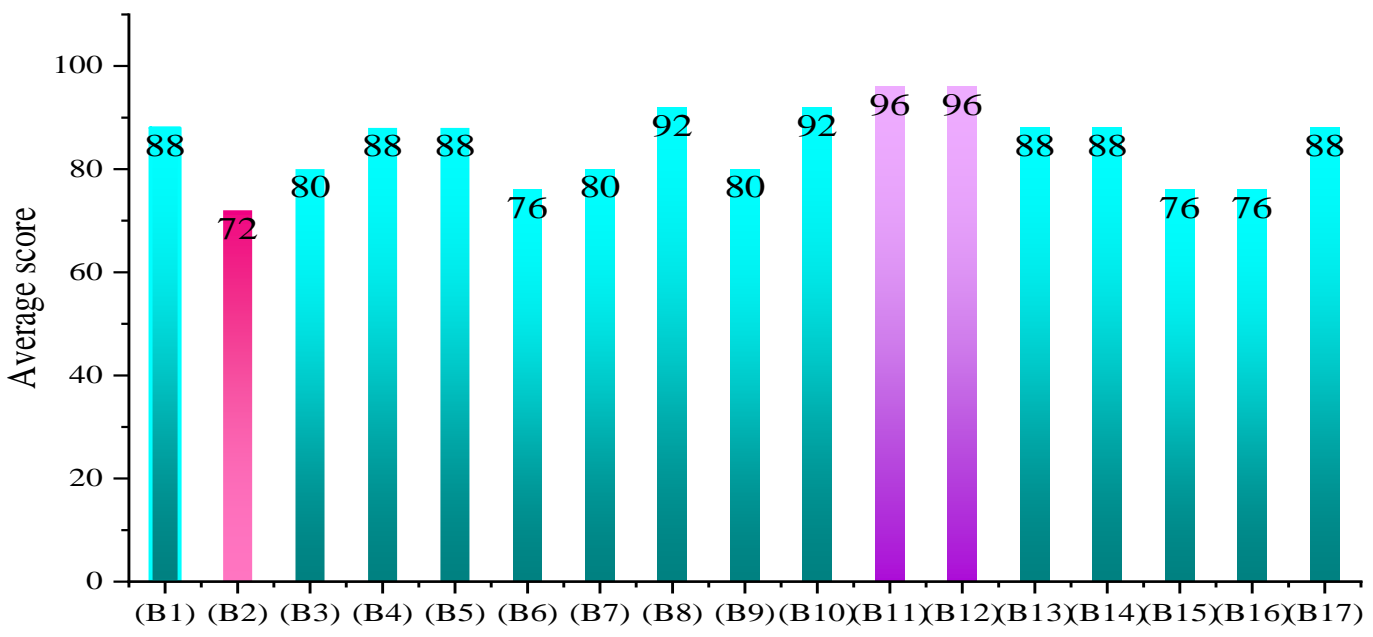

Fig.2 Importance score of secondary evaluation index of sponge city project performance under PPP mode 
Overall, for the first level evaluation index of sponge city project performance under PPP mode, experts believe that the importance of balancing stakeholder satisfaction (A2) is slightly weaker than the other three aspects. Among the secondary indicators, safety measures and management (B11) and risk forecast and control (B12) are the most important, while the financial capacity of all parties (B2) to performance evaluation is relatively small.

\subsection{Analysis and suggestions}

Table 2 Initial judgment matrix of first-rank evaluation index of sponge city project performance under PPP mode

\begin{tabular}{ccccccccc}
\hline & A1 & A2 & A3 & A4 & $r_{j}$ & $w_{j}$ & $u_{j}$ & $y_{j}$ \\
\hline A1 & 1 & 2 & 1 & 1 & 5 & 0.3125 & 0.25 & $31.25 \%$ \\
A2 & 0 & 1 & 0 & 0 & 1 & 0.0625 & 0.25 & $6.25 \%$ \\
A3 & 1 & 2 & 1 & 1 & 5 & 0.3125 & 0.25 & $31.25 \%$ \\
\hline
\end{tabular}

According to the above process, all the performance evaluation indexes of projects under PPP mode are

calculated to get the revised specific weights. See Table 3 .

Table 3 Evaluation index weight of sponge city project performance under PPP mode

\begin{tabular}{|c|c|c|c|c|}
\hline $\begin{array}{c}\text { First-rank evaluation } \\
\text { index }\end{array}$ & $y_{j}$ & $\begin{array}{c}\text { Second-rank } \\
\text { evaluation index }\end{array}$ & $\begin{array}{c}y_{j} \text { (Under the first } \\
\text { rank) }\end{array}$ & $y_{j}$ \\
\hline \multirow[t]{3}{*}{ 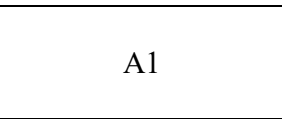 } & \multirow{3}{*}{$31.25 \%$} & B1 & $59.464 \%$ & $18.582 \%$ \\
\hline & & $\mathrm{B} 2$ & $7.109 \%$ & $2.222 \%$ \\
\hline & & B3 & $33.427 \%$ & $10.446 \%$ \\
\hline \multirow{4}{*}{ A2 } & \multirow{4}{*}{$6.25 \%$} & B4 & $40.399 \%$ & $2.525 \%$ \\
\hline & & B5 & $40.399 \%$ & $2.525 \%$ \\
\hline & & B6 & $3.908 \%$ & $0.244 \%$ \\
\hline & & B7 & $15.295 \%$ & $0.956 \%$ \\
\hline \multirow{6}{*}{ A3 } & \multirow{6}{*}{$31.25 \%$} & B8 & $12.906 \%$ & $4.033 \%$ \\
\hline & & B9 & $0.942 \%$ & $0.294 \%$ \\
\hline & & $\mathrm{B} 10$ & $12.906 \%$ & $4.033 \%$ \\
\hline & & B11 & $35.214 \%$ & $11.005 \%$ \\
\hline & & B12 & $35.214 \%$ & $11.005 \%$ \\
\hline & & $\mathrm{B} 13$ & $2.817 \%$ & $0.880 \%$ \\
\hline \multirow{4}{*}{ A4 } & \multirow{4}{*}{$31.25 \%$} & B14 & $45.232 \%$ & $14.135 \%$ \\
\hline & & B15 & $3.342 \%$ & $1.044 \%$ \\
\hline & & B16 & $6.194 \%$ & $1.936 \%$ \\
\hline & & B17 & $45.232 \%$ & $14.135 \%$ \\
\hline
\end{tabular}

The revised weight shows that the balance of stakeholder satisfaction (A2) is still the secondary aspect of the first level indicators. Among the secondary indicators, value for money (B1) is more important in performance evaluation, followed by social citizen's life benefit (B14) and ecological environment benefit (B17); satisfaction of other participants (B6), progress prediction and management (B9) and government supervision and quality inspection (B13) have little impact on performance evaluation.

\subsubsection{Analysis content}

For this case, this paper uses MATLAB software for data processing. Matlab software is commercial mathematical software. The basic data unit is a matrix, with numerical analysis, matrix calculation, scientific data visualization, and nonlinear dynamic system modeling and simulation functions.

Firstly, based on the current results, the pairwise comparison judgment matrix is constructed for each index of the same level. Taking the first level evaluation index as example, the initial matrix is shown in Table 2. 
under the analytic hierarchy process and construct a comprehensive and objective PPP project performance evaluation index system. The system considers the needs of both the government and social capital and pays attention to the performance evaluation of PPP projects from the fundamental goal of PPP projects. It will contribute to PPP project performance management development and promote PPP projects to play an influential role.

\section{REFERENCES}

[1] Wang Hao. Definition and classification of PPP [J]. Urban rail transit, 2004 (05): 23-27.

[2] Hu Li, Zhang Weiguo, ye Xiaosu. Study on benefit allocation model of PPP projects based on shapely modification $[\mathrm{J}]$. Journal of management engineering, 2011,25 (02): 149-154.

[3] Erik Hans Klijn,Joop Koppenjan. The impact of contract characteristics on the performance of public-private partnerships (PPPs)[J]. Public Money \& Management,2016,36(6).

[4] Wang Yumei, Yan Danliang. Research on the performance evaluation system of PPP project based on Balanced Scorecard [J]. Friends of accounting, 2014 (02): 14-17.

[5] Li Yunda, Wen Subin. Management accounting tools and application cases: application of BSC in project performance evaluation [J]. Friends of accounting, 2016 (23): 130-133.

[6] Li Dexin, LV Xiangyu, Wang Jiarui, Liu Xingyu, Han Xiaojuan. SOC estimation of energy storage system based on entropy weight method and Elman neural network $[\mathrm{J}]$. Electronic design engineering, 2020,28 (01): 70-74 + 83 .

[7] Li Shuai, Wei Hong, Ni Xilu, Gu Yanwen, Li Changxiao. Quality evaluation of Ningxia urban human settlements based on AHP and entropy weight method [J]. Journal of Applied Ecology, 2014,25 (09): 2700-2708. 